\title{
PRELIMINARY PROJECT PLAN \\ for \\ LANSCE INTEGRATED \\ FLIGHT PATHS 11a, 11b, 12, \& 13
}

Prepared for

\section{Los Alamos National Laboratory}

Contract No. 0476200199-3U

Report No. 9901572-003

Revision 0

May 3, 2000

Prepared by

\section{ARES CORPORATION}

555 Oppenheimer Drive, Suite 102

Los Alamos, New Mexico 87544 


\section{DISCLAIMER}

This report was prepared as an account of work sponsored by an agency of the United States Government. Neither the United States Government nor any agency thereof, nor any of their employees, make any warranty, express or implied, or assumes any legal liability or responsibility for the accuracy, completeness, or usefulness of any information, apparatus, product, or process disclosed, or represents that its use would not infringe privately owned rights. Reference herein to any specific commercial product, process, or service by trade name, trademark, manufacturer, or otherwise does not necessarily constitute or imply its endorsement, recommendation, or favoring by the United States Government or any agency thereof. The views and opinions of authors expressed herein do not necessarily state or reflect those of the United States Government or any agency thereof. 


\section{DISCLAIMER}

Portions of this document may be illegible in electronic image products. Images are produced from the best available original document. 


\title{
PRELIMINARY PROJECT PLAN for LANSCE INTEGRATED FLIGHT PATHS 11a, 11b, 12, \& 13
}

\author{
Prepared for
}

\section{Los Alamos National Laboratory}

Contract No. 0476200199-3U

Report No. 9901572-003

Revision 0

May 3, 2000

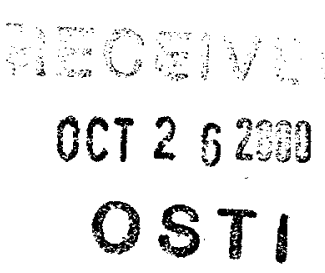

Prepared by: Nawee $\$$ It Juetman

Darrell $\mathrm{H}$. Bultman, PE

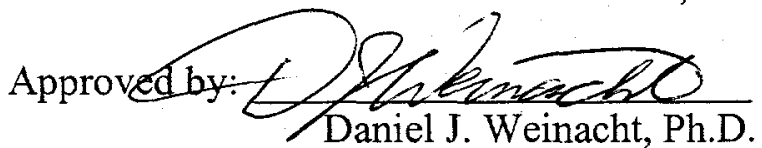

Date:

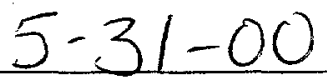




\section{TABLE OF CONTENTS}

1.0 EXECUTIVE SUMMARY

2.0 CONCEPTUAL DESIGN REPORT INTEGRATION OF FLIGHT PATHS 11, 12, AND

13 IN ER-1

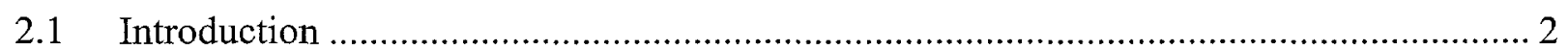

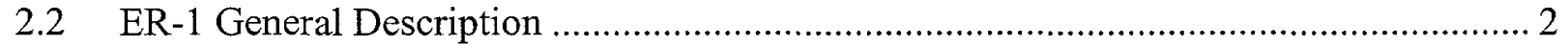

2.3 Integrated Neutron Shutter/Guide ….................................................................. 3

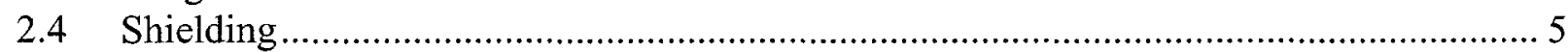

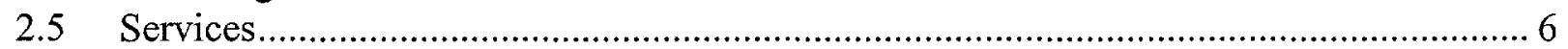

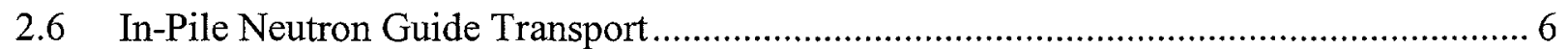

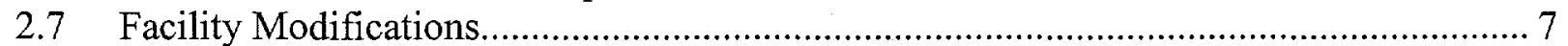

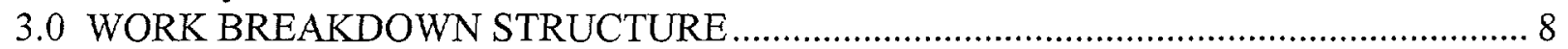

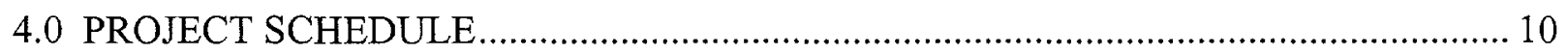

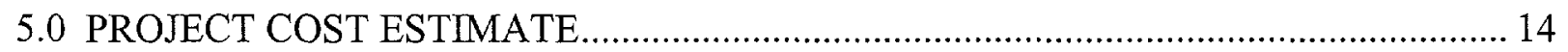

TABLE OF FIGURES

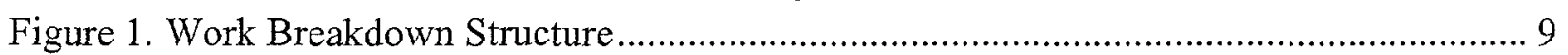

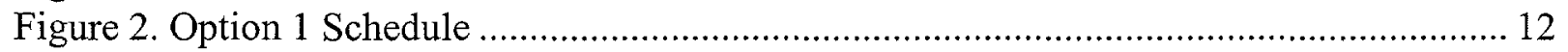

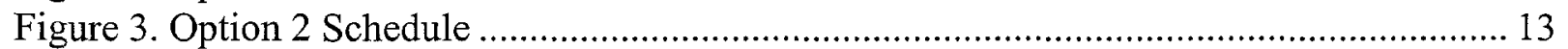

Appendix A:

\section{APPENDICES}

Study Estimate LANSCE Lujan Center Integrated Beam Lines 
PATHS 11a, 11b, 12, \& 13

\subsection{EXECUTIVE SUMMARY}

This Preliminary Project Plan Summarizes the Technical, Cost, and Schedule baselines for an integrated approach to developing several flight paths at the Manual Lujan Jr. Neutron Scattering Center at the Los Alamos Neutron Science Center. It should be noted that these "baselines" have resulted from preconceptual/conceptual efforts and will be further refined in subsequent design phases. For example, the cost "estimate" is intended to serve only as a rough order of magnitude assessment of the cost that might be incurred as the flight paths are developed. Further refinement of the requirements and interfaces for each beamline will permit additional refinement and confidence in the accuracy of all three baselines (Technical, Cost, Schedule). 


\subsection{CONCEPTUAL DESIGN FOR REPORT INTEGRATION OF FLIGHT PATHS 11, 12, AND 13 IN ER-1}

\subsection{Introduction}

This report describes a concept for the integration of several flight paths in Equipment Room 1 (ER1) of the Los Alamos Neutron Scattering Center (LANSCE). In the early planning stages of the Short Pulse Spallation Source (SPSS) program it was determined that, because of the space constraints in ER-1, an integrated approach would be advantageous in the development of these flight paths. Initially, the study included flight paths (FP) 11a, 11b, 12, and 13, but because of funding difficulties and project schedule the first two could not be defined in sufficient detail to include in this report. Hence, the report focuses on FP-12 and FP-13, but does include a shielding concept that encompasses FP-11a and FP-11b.

\subsection{ER-1 General Description}

In ER-1 the configurations of FP-12 and FP-13 are similar in that both employ an in-pile neutron guide followed by an integrated shutter/guide, framing chopper, and freestanding guide that extends into ER-2. Both in-pile guides, each approximately 4-m long, are a unique cantilever design that allows the guide entrance to be in close proximity to the moderator. The guide itself is constructed of a precision steel shell with thin plates of float glass attached to its inner surfaces. This assembly is mounted in a stepped cylindrical steel plug, which serves as a structural strong back for the guide, as well as a radiation shield. Each guide/shield assembly is contained in a stepped cylindrical thimble inserted in the biological shield liner. A dual axis mount located at the outboard end of the thimble allows the guide/shield to be pointed, or aligned parallel with the neutron beam axis. The thimble may be evacuated or back-filled with gaseous helium, depending upon the need to remove heat from the forward end of the guide.

Though the in-pile guides for these flight paths are similar in design and construction, they differ in size and shape. The FP-12 guide, for example, is straight with a 9.5-cm x 9.5-cm clear aperture, while the FP-13 guide has a $9.0-\mathrm{cm} \times 9.0-\mathrm{cm}$ clear aperture at the entrance and a vertical divergence of $0.375-\mathrm{cm} / \mathrm{m}$ that terminates at a location $13-\mathrm{m}$ from the moderator.

In the current concept, with the exception of the chopper, components along FP-12 are isolated from one another by pairs of thin aluminum windows; that is, one window on each interfacing component. For structural integrity these windows, which are approximately $16-\mathrm{cm}$ in diameter, must be about $3-$ mm thick. Over the length of the flight path the total aluminum thickness is about $21-\mathrm{mm}$. This thickness includes that of a thin window at the end of the guide system upstream of the sample station. If such a combined thickness results in an unacceptable neutron flux loss, most of the components may be connected with bellows to provide better optical interfacing between guide segments, as well as a vacuum environment over much of the flight path. Currently, the framing chopper on this flight path is expected to operate at $20 \mathrm{~Hz}$ in the ordinary atmosphere. If it is later determined that a gaseous helium backfill or evacuation is necessary, the chopper housing and motor mounting will need to be modified. 
Connecting components with metal bellows couplings significantly reduces the number of thin windows on FP-13. For example, a metal bellows connects the thimble for the in-pile guide and the shutter/guide chamber, so the components share the same vacuum or helium environment. Similarly, the exit of the chopper is connected to the upstream end of the freestanding guide, so both may be evacuated. Thin windows are required only at the shutter/guide and chopper interface, and at the end of the freestanding guide upstream of the sample station. The resulting equivalent thickness of aluminum is about $9-\mathrm{mm}$.

On both flight paths the neutron guides external to the biological shielding are expected to be of conventional fused silica construction and housed in steel vacuum vessels to provide damage protection. These vessels, in turn, are mounted on long, wide flange structural members, which are supported at various locations on isolation pylons. The pylons are steel reinforced concrete blocks that extend through the ER-1 floor slab and compacted tuff substrate, to a 4-ft thick concrete pad. This provides a very stable, isolated support structure for the neutron optics. The neutron choppers and the down stream end of each shutter/guide will be supported in a similar manner. The upstream end of each shutter/guide rests on a thick concrete apron that surrounds the biological shield pedestal.

A monolithic shield cave constructed of layers of low carbon steel and polyethylene plate encloses components of the four flight paths in ER-1. Roof panels may be removed to provide overhead crane access to components on each of the flight paths. While the existing overhead bridge crane has sufficient radial and azimuthal travel to cover the cave structure and its contents, hook height and lift capacity limitations have an impact on the shielding and shutter designs.

Both flight paths will have dedicated electrical power and signal services for chopper motors, chopper rotor feedback, and motor temperature sensors. Other devices requiring these services include valve position sensors and pressure transducers associated with flight path vacuum systems and thimble helium fill systems. Facility air or dry gaseous nitrogen will be required for operating the shutter/guide rotors, as well as isolation valves for the sets of evacuated flight path components. Pumps and controllers for the vacuum systems will be located in ER-2.

\subsection{Integrated Neutron Shutter/Guide}

Several concepts for integrating a neutron shutter and guide in a fail-safe configuration were reviewed during the preconceptual design phase of the project. Locating the shutter in the outer portion of the biological shield liner takes advantage of the surrounding shield, but the small diameters of the liners on FP-12 and FP-13 preclude such a design. Rather a freestanding shutter/guide positioned immediately downstream of the in-pile guide thimble is proposed for FP-12 and FP-13. Rectangular guillotine, disk, and rotary type shutters were considered.

A vertical guillotine shutter offers the advantages of a narrow cross section, which can be readily integrated with surrounding stationary shielding, and easy implementation of fail-safe closure. Its major disadvantage is that, because its travel trajectory is linear, a void in the surrounding stationary shielding is inevitable. It also requires more headroom than is available in ER-1. 
A disk shutter, with its axis of rotation in a horizontal attitude and normal to the flight path axis, was considered for FP-11a and FP-11b because of their very close proximity. Although this configuration can be readily integrated with surrounding shielding, the design is not practical for FP-12 or FP-13 because of the flight path elevation and the large diameter $(1.5-\mathrm{m})$ of the disk. With the shutter in the closed position, i.e., with the guide oriented vertically, the overhead shield thickness in the vicinity of the upper end of the guide is limited to about $0.6-\mathrm{m}$.

The rotary shutter is most practical for ER-1 because it is readily integrated with surrounding stationary shielding, it allows for maximum overhead shielding, and it requires no shielding voids for shutter motion. It also offers the advantage of locating its axis of rotation, relative to the flight path axis, in several positions. This offset capability allows for simpler integration of shutters with components on adjacent flight paths.

Greatly limited access to the shutter/guide requires that it be robust and highly reliable. To meet this requirement, construction materials, particularly those used in the rotor motion control (e.g., prime mover, position sensors), must be limited to inorganics or be somewhat insensitive to neutron and gamma radiation. The proposed concept incorporates an all-metal pneumatic cylinder assembly, which requires no elastomer seals, with a positively sealed linear metal bellows feedthrough to provide the necessary linear-to-rotary motion conversion. This design not only locates the prime mover outside the shutter vacuum vessel, but also eliminates the need for a rotary feedthrough penetration in the vessel wall. Direct rotary feedthroughs are generally limited to low torque applications if they are positively sealed with metal bellows, or they require elastomer seals or combinations of elastomer and graphite seals if they have high torque capacity. The control valve system for the pneumatic cylinder may be located in ER-1 outside the shield cave or in ER-2.

Sensors for indicating the open and closed positions of the rotor may be of two types, both of which are commercially available in radiation hardened models. Electromechanical limit switches offer a simple method for indicating position, but because they are strictly on-off devices they are proximity sensors at best. A linear variable differential transformer (LVDT), by contrast, produces a specific output voltage for each position of its core, which is typically activated by an external force. In this case the rotor applies the force as it moves into its stroke end position. Thus, when the rotor is aligned and hard stops are set to limit its rotation, the LVDT may be adjusted to output a finite voltage, or zero voltage at its core null position. If the rotor should drift away from a hard stop it will be indicated by a change in the LVDT output. Because they have a finite amount of pretravel and overtravel (typically on the order of $0.5-\mathrm{mm}$ ) electromechanical switches can allow drift to go undetected. Lateral offset or misalignment of a neutron guide must be less than $0.10-\mathrm{mm}$, which is within the range of the LVDT. Also, the LVDT is physically simpler and more robust than the electromechanical switch. A third sensor in the control system indicates the midstroke position of the rotor and is used to trigger a deceleration circuit in the pneumatic control system. This sensor may be a variable reluctance proximity transducer or a similar type device of radiation hardened design.

The rotor is a rigid monolithic structure with an assemblage of tungsten, steel, and polyethylene blocks mounted in a wide slot that parallels the rotor axis. A neutron guide, mounted in a separate tubular housing, is located in a second slot diametrically opposite the shielding. This assembly is 
supported by a set of spherical roller bearings mounted in a trunion with bearing retainer caps. Rigid plates forming the trunion are integral parts of the lower half of the cylindrical vacuum vessel and a rigid base unit. This geometry has substantial torsional and bending stiffness and may be readily integrated with surrounding stationary shielding. Horizontal and vertical translations, as well as roll, pitch, and yaw adjustments are provided in the base unit for coarsely positioning the rotor during the initial installation. Removing the top half of the vacuum vessel exposes the rotor, its position sensors and bearings, and the neutron guide. Rotor bearings are lubricated with a low vapor pressure lubricant such as molybdenum disulfide or tungsten disulfide.

To facilitate in situ replacement of the neutron guide without realignment the guide is mounted in a separate tube equipped with three kinematic mounts. The guide is initially aligned in its housing with spring pads and screws similar to those commonly used in other guide applications. This assembly is then mounted in the shutter rotor and aligned with the three kinematic mounts during the initial installation. Key relationships between the guide and its tube and between the tube and kinematic mounts may then be reproduced on a cold guide assembly being prepared for in situ replacement of one that has failed.

\subsection{Shielding}

In the preconceptual design phase of this project shielding of individual flight paths was considered but was judged to be cost prohibitive because of geometric complexities. Limited space between the flight paths would require that each component of a flight path be closely enveloped by the shielding. Further complexities became apparent when the layered composite nature of the shielding was considered. Enclosing the four flight paths in a monolithic shield cave may require more material, but does not pose the complex geometry problems that ultimately result in significantly greater fabrication and installation costs. It also provides the flexibility of adding localized shielding where it is needed.

The proposed shield concept is a large, wedge shaped structure composed of steel and polyethylene plates assembled in thick modular panels that can be handled with the existing overhead bridge crane. Its approximate outside dimensions are 5.5-m long $\times 7-\mathrm{m}$ wide $\times 2.8-\mathrm{m}$ high, and its total weight is approximately 350 tons, of which $75 \%$ (by volume) is steel and $25 \%$ is polyethylene. The roof and downstream wall (i.e., the wall facing the interior of the wall separating ER-1 and ER-2) are approximately 40-in. (1-m) thick. As recommended, the roof and wall are assembled in the following composition (from inside to outside): 2" $-\mathrm{CH}_{2}\left(5 \% \mathrm{~B}\right.$ ), 6" - Fe, 2" $-\mathrm{CH}_{2}$ (std), 24" - Fe, $1 "-\mathrm{CH}_{2}(5 \% \mathrm{~B}), 4$ " $-\mathrm{CH}_{2}(\mathrm{std})$, and 1" $-\mathrm{CH}_{2}(5 \% \mathrm{~B})$. For the purpose of this project the walls interfacing FP-10 and FP-14 are shown as approximately $0.5-\mathrm{m}$ thick in the same material proportions. It is understood that this shielding must eventually be integrated with that of FP-10 and FP-14. Additional shielding of lesser thickness surrounds the freestanding guides extending between the downstream shield wall and the ER-1 wall. Throughout the shield structure the panels are overlapped to eliminate direct shine paths for radiation.

Modular panels comprising the roof structure are supported by a system of columns, wide flange beams, and T-beams. The design was developed with overhead crane access and maintenance in 
mind. T-beams, rather than wide flange beams, are used to span the shutter/guides because of the limited overhead space between the latter's vacuum vessel and the cave roof. These beams may be removed for full overhead access to the shutter/guides. Although it is not shown on the drawings, a large door in the downstream shield wall near the ER-1 overhead door is anticipated. Because of the bridge crane's low hook height such a door is necessary for ingress and egress of fully assembled components. For the same reason the door opening must extend to the top of the downstream shield wall.

\subsection{Services}

Each flight path has dedicated vacuum, pneumatic, gas, and electrical services. Since the design operating pressure for both FP-12 and FP-13 is in the range of 1.0 torr to 1.0 millitorr, a manifold system served by a single one-stage rotary vane pump is sufficient for each flight path. A hermetically sealed pump exhausted through a HEPA filter system is recommended. A typical leg from the manifold serving one or two flight path components includes a pressure transducer, pneumatically operated isolation valve, and in-line bellows for vibration isolation and alignment. The manifold is isolated from the pump, which is located in ER-1, by another pneumatically operated valve. An additional pressure transducer is located upstream of this valve. Pneumatic service to each valve may be provided by the facility compressed air system or a dry nitrogen gas supply. Each leg of this system includes a pressure transducer and shut-off valve. Electrical services to each valve include low voltage (typically $5 \mathrm{VDC}-28 \mathrm{VDC}$ ) for solenoid-operated air valves and valve position limit switches.

If helium is required for the removal of heat from the front end of the in-pile guides on FP-12 and FP-13, a simple distribution manifold is required. Both legs of this manifold will have electrically or pneumatically operated shut-off valves and pressure transducers located in ER-1 outside the shield cave.

Pneumatic service for the shutter/guide actuating cylinder may also be provided by the facility compressed air system or a dry nitrogen gas supply. This system may be arranged as the helium distribution system with each leg equipped with an electrically or pneumatically operated shut-off valve and pressure transducer located in ER-1 outside the shield cave. Electrical service to each shutter/guide is low voltage (typically 5VDC - 28VDC) for the position sensors.

Neutron choppers on FP-12 and FP-13 require only electrical service for motor power and signal transmission from the motor's temperature sensors and rotor position detection system. Ready-made cables with motor and controller interface connectors are available from the motor manufacturer in lengths to $30-\mathrm{m}$.

\subsection{In-Pile Neutron Guide Transport}

Before construction of the shield cave or installation of components on either FP-12 or FP-13 commences, the in-pile guides for these flight paths must be installed in their respective thimbles. The guide transporter is designed for transferring the guide in its shield plug to the biological shield, 
aligning it with the thimble, and inserting it. Vertical and horizontal translations as well as rotations are integrated in the transporter design to provide the needed precision for insertion of the guide. Proper alignment is important because the forward 1.2 meters of the cantilevered guide are exposed and the clearance for this portion of the guide in the thimble's forward end is small.

Ingress and egress of the transporter must be through the overhead door connecting ER-1 and ER-2. Segments of the shielding and vacuum pipe on FP-14 must be removed for this purpose.

\subsection{Facility Modifications}

Components along each flight path may include shutter/guides, neutron choppers, and free-standing guides. To achieve maximum performance from each flight path, mitigate the effects of vibration and facility floor deformation, and facilitate component alignment, it is recommended that the beamline components be isolated via engineering design and vibration isolation. These aspects of the design logically fall within the detailed design phase.

The conceptual shielding support structure (columns and beams) has been depicted in the conceptual drawing package and discussed in Section 2.4. Although preliminary scoping calculations have been used to size the structural members, detailed structural engineering analyses need to be performed (e.g., a seismic analysis probably needs to be performed) in subsequent design phases. It is recommended that these structural analyses and the resulting construction drawings be reviewed and stamped by a licensed Professional Engineer.

Each of the beamlines will require various utilities (e.g., electrical, vacuum, etc.). Specification and design of these ancillary services will be performed during the detailed design phase. 


\subsection{WORK BREAKDOWN STRUCTURE}

The Integrated Beam Lines Project Level-3 Work Breakdown Structure (WBS) is shown in Fig. 1. This WBS provides a compilation of all project deliverables, which form the basis of the technical scope, cost and schedule, as described in other sections of this preliminary project plan. The main elements of the WBS (Level 2) include: 1.1 Project Management; 1.2 Design Activities; 1.3 Procurement; 1.4 Construction, Installation \& Testing; and 1.5 Safety / Regulatory Activities. 


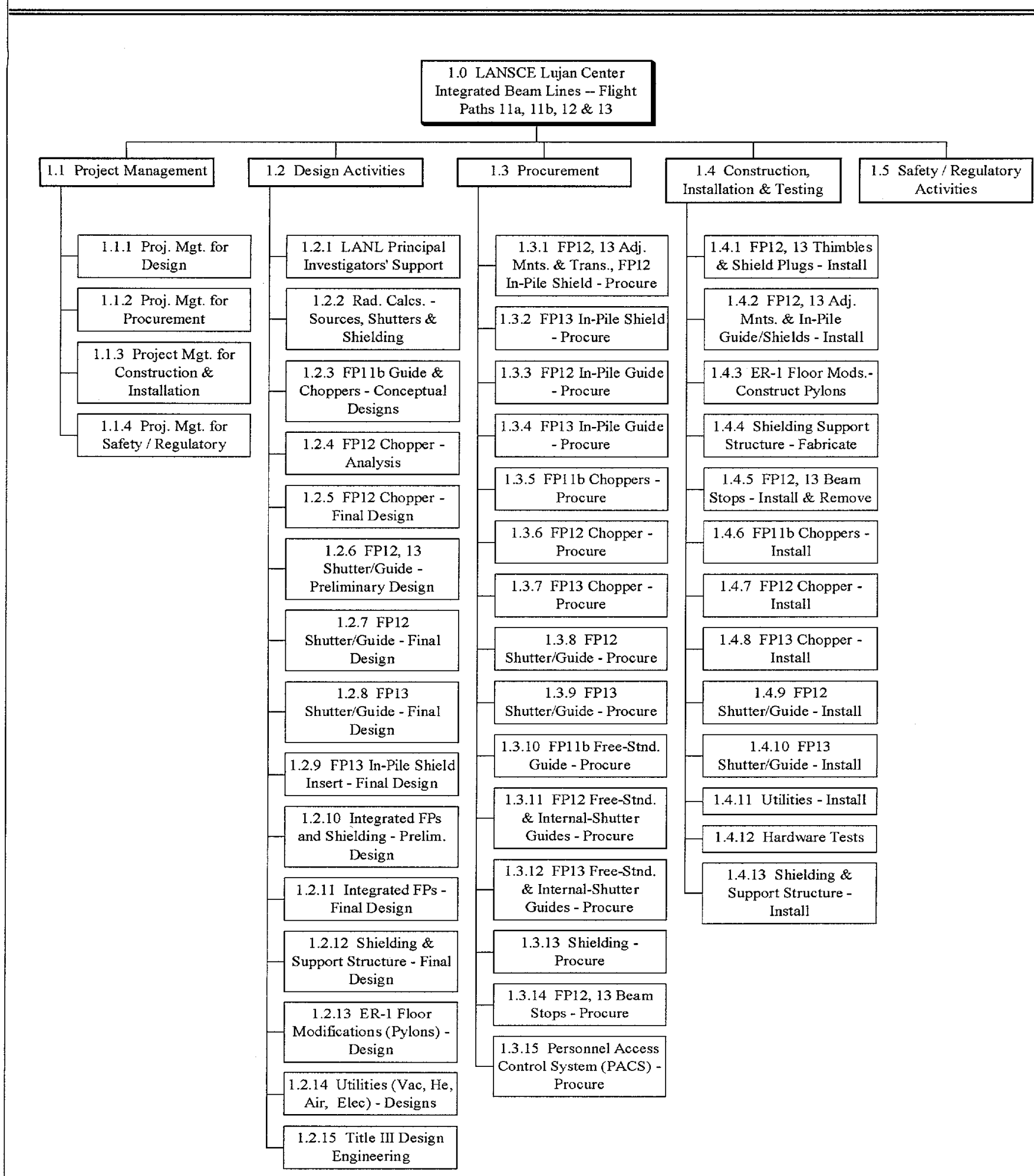

Figure 1. Work Breakdown Structure 


\subsection{PROJECT SCHEDULE}

A preliminary project schedule has been developed based on an understanding of the project scope that was gained while developing the Conceptual Design and from discussions with LANSCE-12 personnel. The schedule includes those tasks that are necessary to accomplish or deliver the elements delineated in the project WBS.

Two schedule options have been considered. They are based on two possible run-time/shutdown operating cycles of the LANSCE Neutron Scattering Center, which were identified by LANSCE-12 personnel. Other operating cycles might also be considered but were not evaluated in this scheduling effort. Both schedules include the tentatively planned shutdown period from October 1 , 2000 to February 28, 2001 ( 5 months). Thereafter, the Option 1 Schedule shown in Figure 2 includes a repeating 8-month run-time and 4-month shutdown cycle, and the Option 2 Schedule shown in Figure 3 is based on a repeating 4-month run-time and 2-month shutdown cycle.

Both schedules include tasks for the design, procurement (including fabrication), and installation of beam line hardware and radiation shielding in ER-1 for Flight Paths (FP) 11a, 11b, 12 and 13.

Specific tasks for LANL Project Management and for Safety/Regulatory work are not included, as they are expected to be hammock-type tasks that span the overall duration of the schedule. It is also expected that most of the Safety/Regulatory work will occur during the modification of ER-1 and the installation of hardware.

The scope of the work required for FPs $11 \mathrm{a}$ and $11 \mathrm{~b}$ were not fully defined at the time of the schedule preparation. In general it was known that FP 11 a would remain essentially unchanged, and FP $11 \mathrm{~b}$ might be retrofitted with new sections of freestanding neutron guides and either one or two new choppers. To capture these requirements, two 8-month duration tasks for hardware design and procurement were included as "placeholders" in the schedules.

Both schedules show that preliminary designs of the shutter/guides and the integrated shielding package must lag the radiation shielding calculations, which will provide essential input to those designs. Durations of the design and procurement tasks (except neutron guides) were estimated by ARES Corporation engineers, based on experience from similar work. Durations for the neutron guide procurements are taken from the cost and schedule quotations provided to LANL by guide vendors. Procurements of FP 13 in-pile guides and the framing chopper are delayed until November of FY2001 to coincide with the anticipated availability of funding. Also, in general, procurement tasks that follow final design tasks are delayed 6-weeks to account for the time required to initiate requests for proposals and issue procurement contracts.

Tasks in Schedules 1 and 2 are identical except for the beam-operating cycles described above and the specific hardware-installation tasks. The approach used in Schedule 1 is to install hardware as soon as it has been procured, during the earliest possible shutdown period. In this case, the 4-month shutdown in FY2002 will not be long enough to accomplish all installation tasks, with some needing to be delayed until the following shutdown, or the shutdown period extended. Schedule 2 follows a similar approach, but includes the installation of beam stops against the biological shield on FPs 12 
and 13 after the in-pile shields and guides are installed, to allow continuation of work in ER-1 during the LANSCE run time. The potential benefits of this approach are minimized because the delivery of shielding and neutron guide hardware will lag the installation of the beam stops by several months, thus delaying the installation of shielding and guides. In this case also, the shutdown in FY2002 will not be long enough to accommodate all installation tasks, but with the shutter/guides in place on FPs 12 and 13, construction and installation work in ER-1 might be able to continue during the LANSCE run time.

In the preliminary schedules, the least well defined and highest risk tasks are the hardware installation tasks. To some extent, the final design configurations and the risks of damaging delicate hardware (e.g., neutron guides) or compromising alignment during installation will influence the sequence in which hardware can be installed in ER-1. As the hardware designs and their integration into ER-1 are further developed, the required installation tasks will become better defined. 


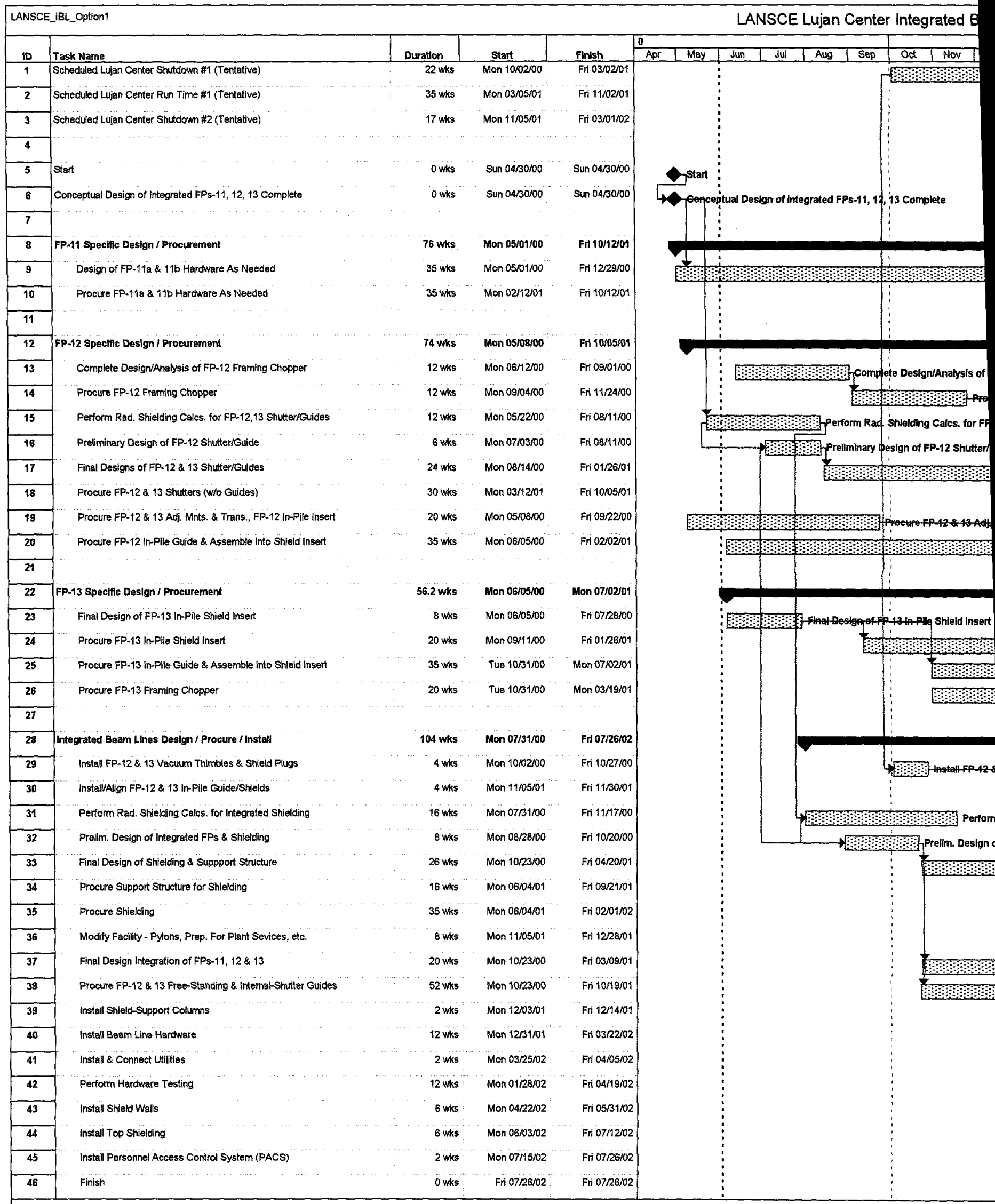

\begin{tabular}{|c|c|c|c|c|c|c|c|}
\hline $\begin{array}{l}\text { Project: Lujan Center integrated Beam Li } \\
\text { Date: Thu } 0610100\end{array}$ & Task & 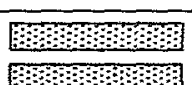 & Progress & 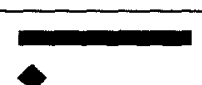 & Summary & $\frac{1}{4}$ & Rolled Up Critical Task \\
\hline
\end{tabular}


Lines - Flight Paths 11a, 11b, 12 \& 13 (Option 1)
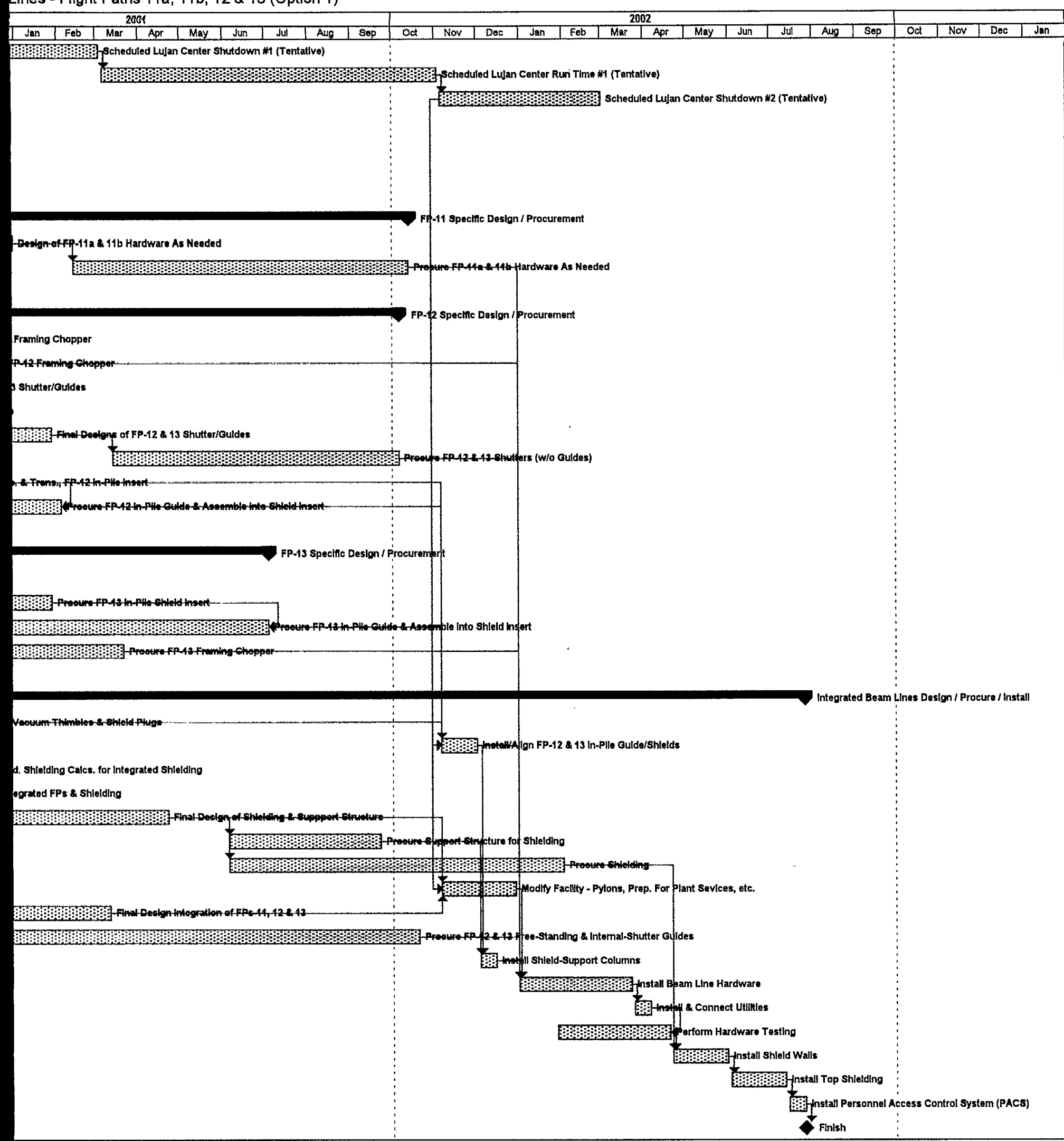
O External Tasks 


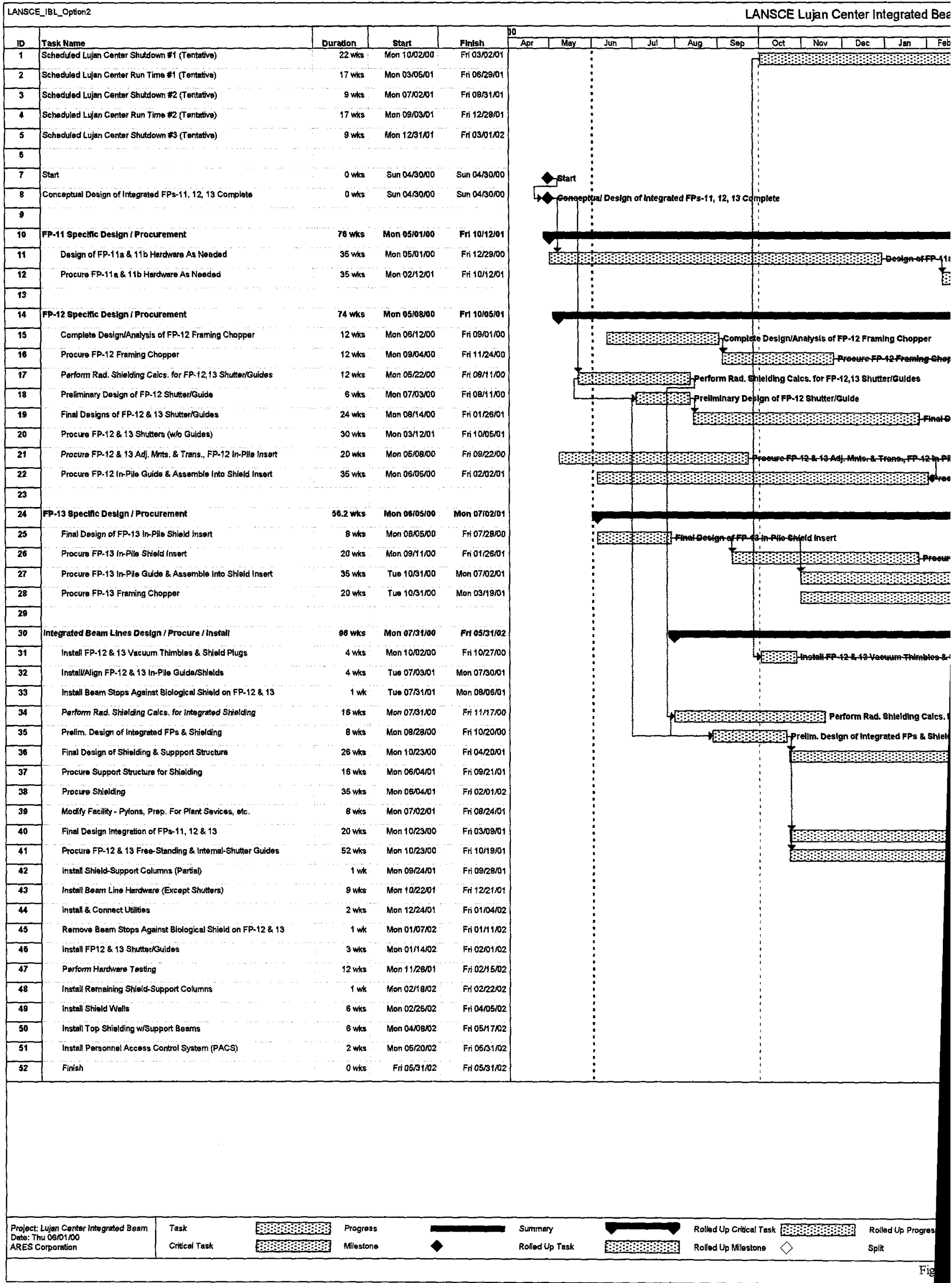




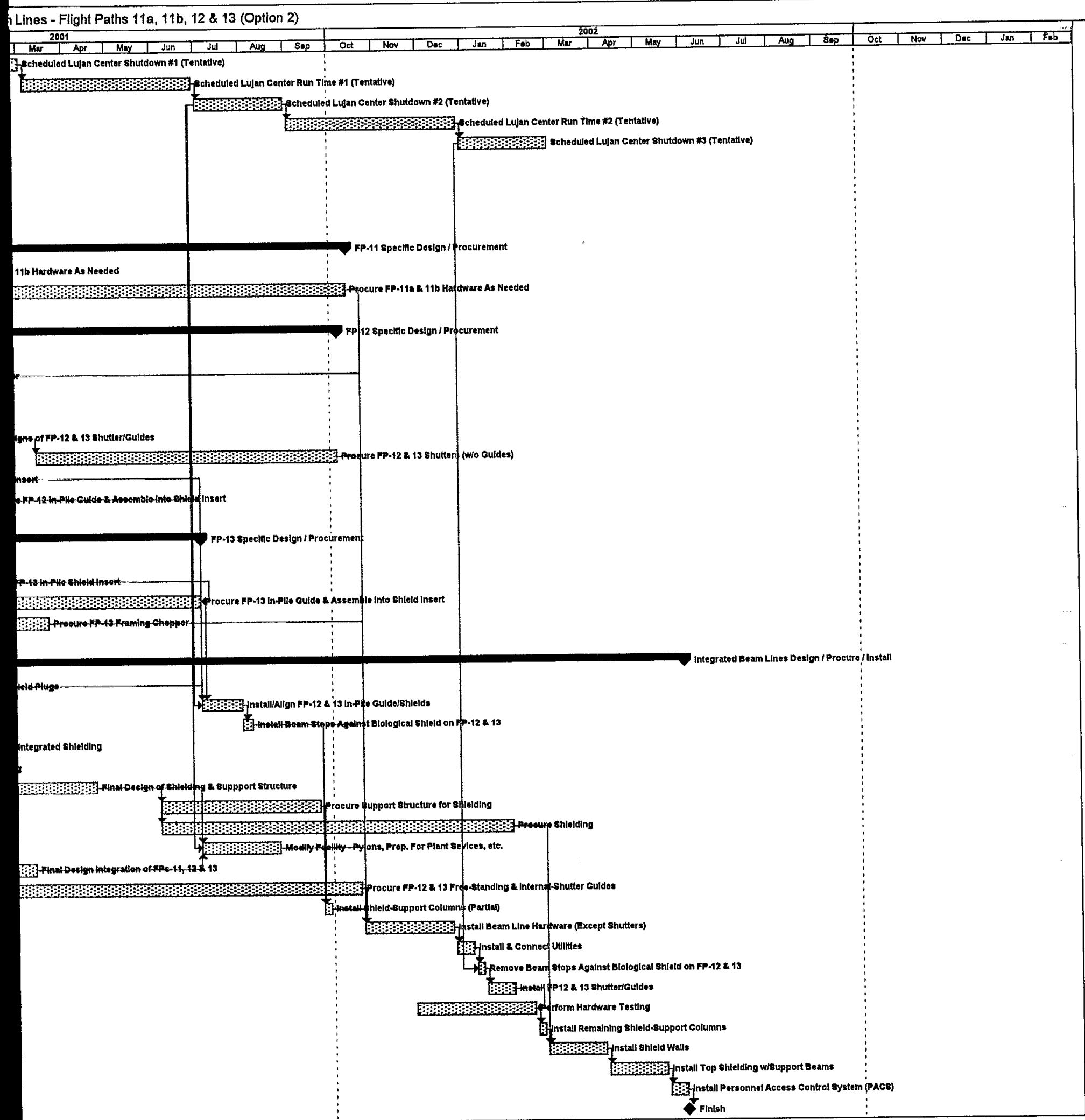




\subsection{PROJECT COST ESTIMATE}

The preliminary cost estimate for the Integrated Beam Lines Project consists of individual costs and contingencies for each Level 3 WBS element, which are rolled up to summary level WBS elements. LANL overheads, escalation, and New Mexico gross receipts tax are included in the estimates. The summary costs for the project are given in Table 1. Detailed cost estimates for lower level WBS elements are included in Appendix A. These estimates can be refined and the contingency adjusted as the hardware designs and their integration into ER-1 are further developed.

\section{Table 1. DETAILED ESTIMATING WORKSHEET BY WBS Preliminary Cost Estimate}

WBS 1.0 LANSCE Lujan Center Integrated Beam Lines - Flight Paths 11a, 11b, 12 \& 13

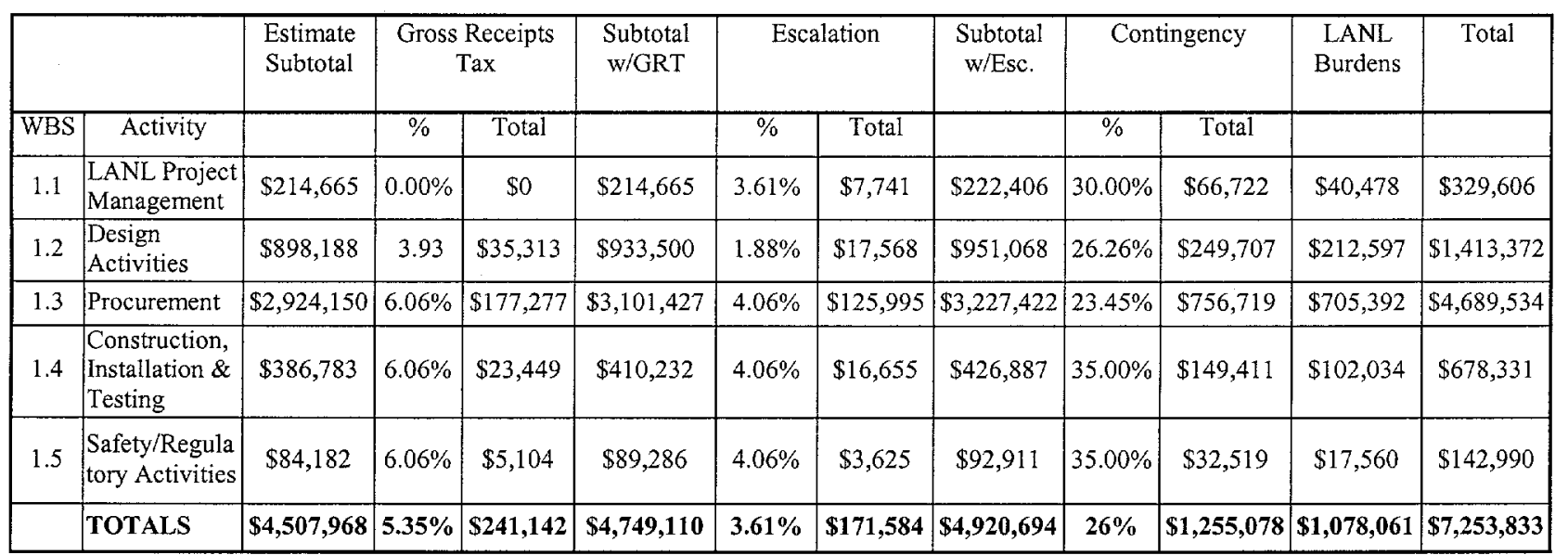

The detailed cost estimate in Appendix A includes specific notes that describe the basis and assumptions for the cost elements. As noted, the cost for Project Management is assumed to be 5\% of the combined design, procurement, construction and safety/regulatory cost, following standard guidelines for DOE projects. The Safety/Regulatory activities are assumed to require funding estimated at $2 \%$ of design, procurement and construction costs. Manpower efforts for other tasks that will be performed primarily by LANL personnel (e.g., LANL Principal Investigators' Support, and Radiation Shielding Calculations) were estimated by LANSCE-12 staff. ARES Corporation developed estimates for the design, procurement and installation tasks based on experience from developing the Conceptual Design and from completing similar projects, with additional input from LANSCE-12 personnel. Procurement costs for the various neutron guides were taken from cost quotations provided to LANL by guide vendors, except the FP $11 \mathrm{~b}$ freestanding guide for which an estimate was provided by LANSCE- 12 . 
PATHS 11a, 11b, 12, \& 13

\section{APPENDIX A}

Preliminary Cost Estimate

LANSCE Lujan Center Integrated Beam Lines

9901572 


\section{ARES Corporation Task 9901572 \\ DETAILED ESTIMATING WORKSHEETS BY WBS \\ LANSCE Lujan Center Integrated Ream Lines \\ Estimate Basis}

\section{GENERAL}

Escalation was calculated based on the weighted mid-point of major activities. A 3.25\% escalation figure for all years was utilized.

Estimated costs were based on RS means (adjusted to reflect LANL 1999 Davis Bacon labor rates), estimators judgement, and vendor budgetary quotes, and costs for various previously completed activities.

It was assumed for purposes of this estimate that design would begin in FY2001 with construction/testing completed in FY2002.

\section{WBS 1.1 - PROJECT MANAGEMENT}

The cost for Project Management was based on an assumption that Project Management should cost approximately 5\% of the combined design, procurement, construction, installation $\&$ testing, and safety/regulatory costs.

\section{WBS 1.2 - DESIGN ACTIVITIES}

The cost for Design Activities was based on detailed spreadsheets for type of personnel and manhours for each major activity.

The Title III Design effort was estimated using an allocation of $25 \%$ of final design costs.

Gross Recepts tax was not included on those tasks that are expected to be performed by LANL personnel.

\section{WBS 1.3 - PROCUREMENT}

Budgetary quotes where obtained from equipment vendors when available.

Procurement estimates for neutron guides for flight paths 12 and 13 (WBS 1.3.3, 1.3.4, 1.3.11 and 1.3.12) are from quotations provided to LANL by neutron guide vendors.

Procurement estimates for all choppers, FP11b neutron guides, beam stops, and the PACS (WBS 1.3.5, 1.3.6, 1.3.7, 1.3.10, 1.3.14 and 1.3.15) were provided by LANSCE-12 personnel.

WBS 1.4 - CONSTRUCTION, INSTALLATION \& TESTING 
A fully burdened labor rate was utilized for each craft

Costs for each unique activity were estimated using National rates for similar activities and adjusted per engineering judgement.

Contingency was applied at the work item level. A detailed take off of all materials was performed. Allocations for non-task specific work (construction support, testing, etc.) were based on estimators judgement and material and labor estimates.

Catalog/Vendor data was utilized for all major components.

No allowance for overtime was included.

Quantities for materials were taken from drawings and engineering judgement.

The cost for major equipment was based on vendor budgetary quotes.

Allocations for equipment rental were made based on the estimator's judgement of construction practices.

Manufacturers' overhead and profit was not charged on major GFE equipment. A procurement fee of $10 \%$ was charged on all material unless vendor quotes included these costs.

Crew composition was based on estimator's understanding of construction practices.

Foreman and General Foreman wage differences (10\% Foreman and $11 \%$ General Foreman) were calculated in the installation unit cost of each item, and assumed each was a working craftsman.

A $10 \%$ "Construction Support Allowance" was applied to all construction activities. This allowance provides for contractor safety support, field engineering support, field QA support, area cleanup, dust control, etc.

\section{WBS 1.5 - SAFETY/REGULATORY ACTIVITIES}

It is assumed this will require funding estimated at $2 \%$ of design, procurement and construction, installation $\&$ testing costs. 


\section{ARES Corporation Task 9901572 \\ DETAILED ESTIMATING WORKSHEETS BY WBS \\ LANSCE Lujan Center Integrated Beam Lines \\ Contingency Analysis}

\section{WBS 1.1 - PROJECT MANAGEMENT}

A contingency of $30 \%$ was applied to this activity due to the following reasons: 1) construction is more complicated than typical, 2) multiple procurements and construction activities must be co-ordinated, and 3) the project involves many different LANL organizations.

\section{WBS 1.2 - DESIGN ACTIVITIES}

A $25 \%$ contingency was applied to the design tasks for the following reasons: Base costs for designs considered the types of drawings required, and were prepared by engineers familiar with these types of activities, using a bottoms-up approach to estimate the required manhour efforts (except Title III Design). For four activities with higher uncertainties, a 35\% contingency was used.

\section{WBS 1.3 - PROCUREMENT}

A moderate contingency of $30 \%$ was applied to this WBS due to the level of detail available on costs of Procurement, with the following exceptions: 1) a fixed-price procurement of FP12, 13 Adj. Mnts. \& Transporter, \& FP12 In-Pile Shield (WBS 1.3.1) is already underway, thus a $0 \%$ contingency is used; and 2) vendor quotes for the various neutron guides have been obtained but the dates through which they were valid have passed so a contingency of $15 \%$ is used.

\section{WBS 1.4 - CONSTRUCTION, INSTALLATION \& TESTING}

A high level of contingency was applied to these activities (35\%), due to the following reasons: 1) construction is complex and dependent on conditions found during actual design and construction, 2) there are multiple contracts and LANL organizations to coordinate, 3) laboratory requirements for beam operation are uncertain at this time, and 4) the type of construction involved is different than typically encountered.

\section{WBS 1.5 - SAFETY/REGULATORY ACTIVITIES}

A high level of contingency was applied to these activities (35\%), due to the following reasons: 1 ) interaction with regulatory agencies will be confusing, 2) tie-ins to existing permitted systems are required, 3) no regulatory/safety plan has been written, and 4) overall cost is not very great, therefore minor issues utilize a large percentage of contingency. 


\section{DETAILED ESTIMATING WORKSHEET BY WBS}

LANSCE Lujan Center Integrated Beam Lines

9901572

Preliminary Cost Estimate

WBS 1.0 LANSCE Lujan Center Integrated Beam Lines - Flight Paths 11a, 11 b, 12 \& 13

\begin{tabular}{|c|c|c|c|c|c|c|c|c|c|c|c|c|}
\hline & \multirow{2}{*}{$\begin{array}{l}\text { Estimate } \\
\text { Subtotal }\end{array}$} & \multicolumn{2}{|c|}{ Gross Receipts Tax } & \multirow{2}{*}{$\begin{array}{l}\text { Subtotal } \\
\text { w/GRT }\end{array}$} & \multicolumn{2}{|c|}{ Escalation } & \multirow{2}{*}{$\begin{array}{l}\text { Subtotal } \\
\text { w/Esc. }\end{array}$} & \multicolumn{2}{|c|}{ Contingency } & \multirow{2}{*}{$\begin{array}{c}\text { LANL } \\
\text { Burdens }\end{array}$} & \multirow[t]{2}{*}{ Total } \\
\hline WBS & Activity & & $\%$ & Total & & $\%$ & Total & & $\%$ & Total & & \\
\hline 1.1 & LANL Project Management & $\$ 214,665$ & $0.00 \%$ & $\$ 0$ & $\$ 214,665$ & $3.61 \%$ & $\$ 7,741$ & $\$ 222,406$ & $30.00 \%$ & $\$ 66,722$ & $\$ 40,478$ & $\$ 329,606$ \\
\hline 1.2 & Design Activities & $\$ 898,188$ & $3.93 \%$ & $\$ 35,313$ & $\$ 933,500$ & $1.88 \%$ & $\$ 17,568$ & $\$ 951,068$ & $26.26 \%$ & $\$ 249,707$ & $\$ 212,597$ & $\$ 1,413,372$ \\
\hline 1.3 & Procurement & $\$ 2,924,150$ & $6.06 \%$ & $\$ 177,277$ & $\$ 3,101,427$ & $4.06 \%$ & $\$ 125,995$ & $\$ 3,227,422$ & $23.45 \%$ & $\$ 756,719$ & $\$ 705,392$ & $\$ 4,689,534$ \\
\hline 1.4 & $\begin{array}{l}\text { Construction, Installation \& } \\
\text { Testing }\end{array}$ & $\$ 386,783$ & $6.06 \%$ & $\$ 23,449$ & $\$ 410,232$ & $4.06 \%$ & $\$ 16,655$ & $\$ 426,887$ & $35.00 \%$ & $\$ 149,411$ & $\$ 102,034$ & $\$ 678,331$ \\
\hline 1.5 & Safety/Regulatory Activities & $\$ 84,182$ & $6.06 \%$ & $\$ 5,104$ & $\$ 89,286$ & $4.06 \%$ & $\$ 3,625$ & $\$ 92,911$ & $35.00 \%$ & $\$ 32,519$ & $\$ 17,560$ & $\$ 142,990$ \\
\hline & TOTALS & $\$ 4,507,968$ & $5.35 \%$ & $\$ 241,142$ & $\$ 4,749,110$ & $3.61 \%$ & $\$ 171,584$ & $\$ 4,920,694$ & $26 \%$ & $\$ 1,255,078$ & $\$ 1,078,061$ & $\$ 7,253,833$ \\
\hline
\end{tabular}


DETAILED ESTIMATING WORKSHEET BY WBS

LANSCE Lujan Center Integrated Beam Lines

9901572

Preliminary Cost Estimate

WBS 1.1 LANL Project Management

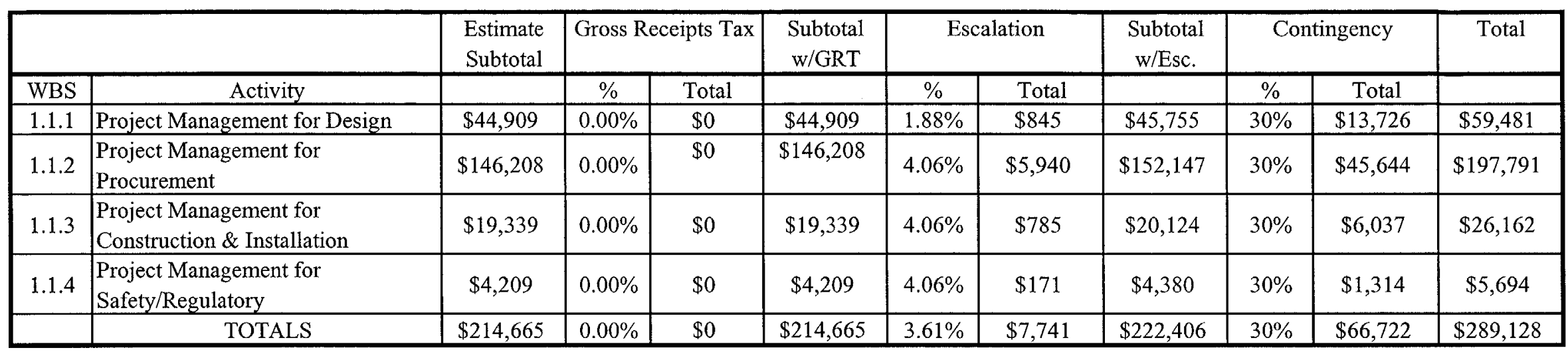


DETAILED ESTIMATING WORKSHEET BY WBS

LANSCE Lujan Center Integrated Beam Lines

9901572

Preliminary Cost Estimate

WBS 1.2 Design Activities

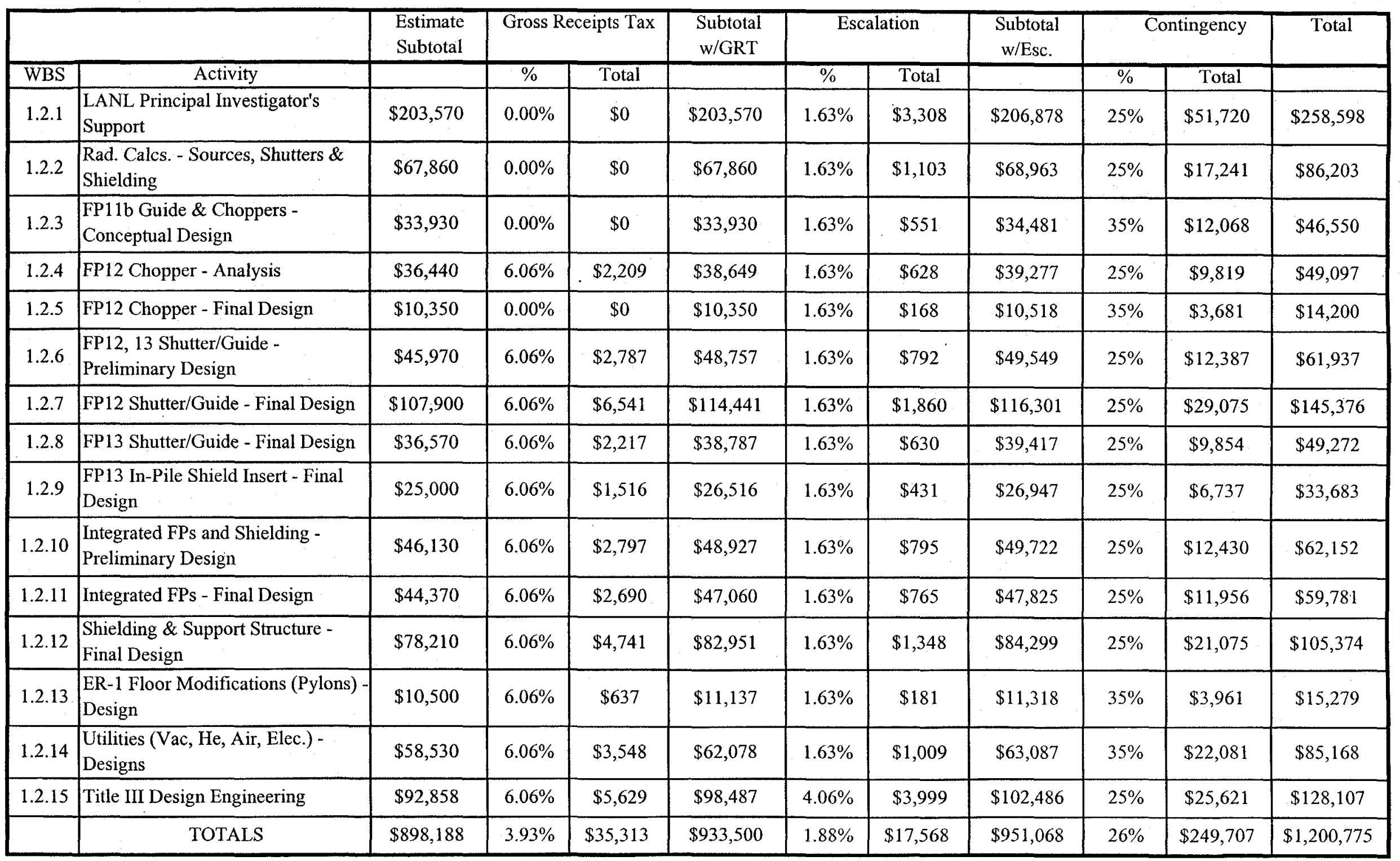


DETAILED ESTIMATING WORKSHEET BY WBS

LANSCE Lujan Center Integrated Beam Lines

9901572

Preliminary Cost Estimate

WBS 1.3 Procurement

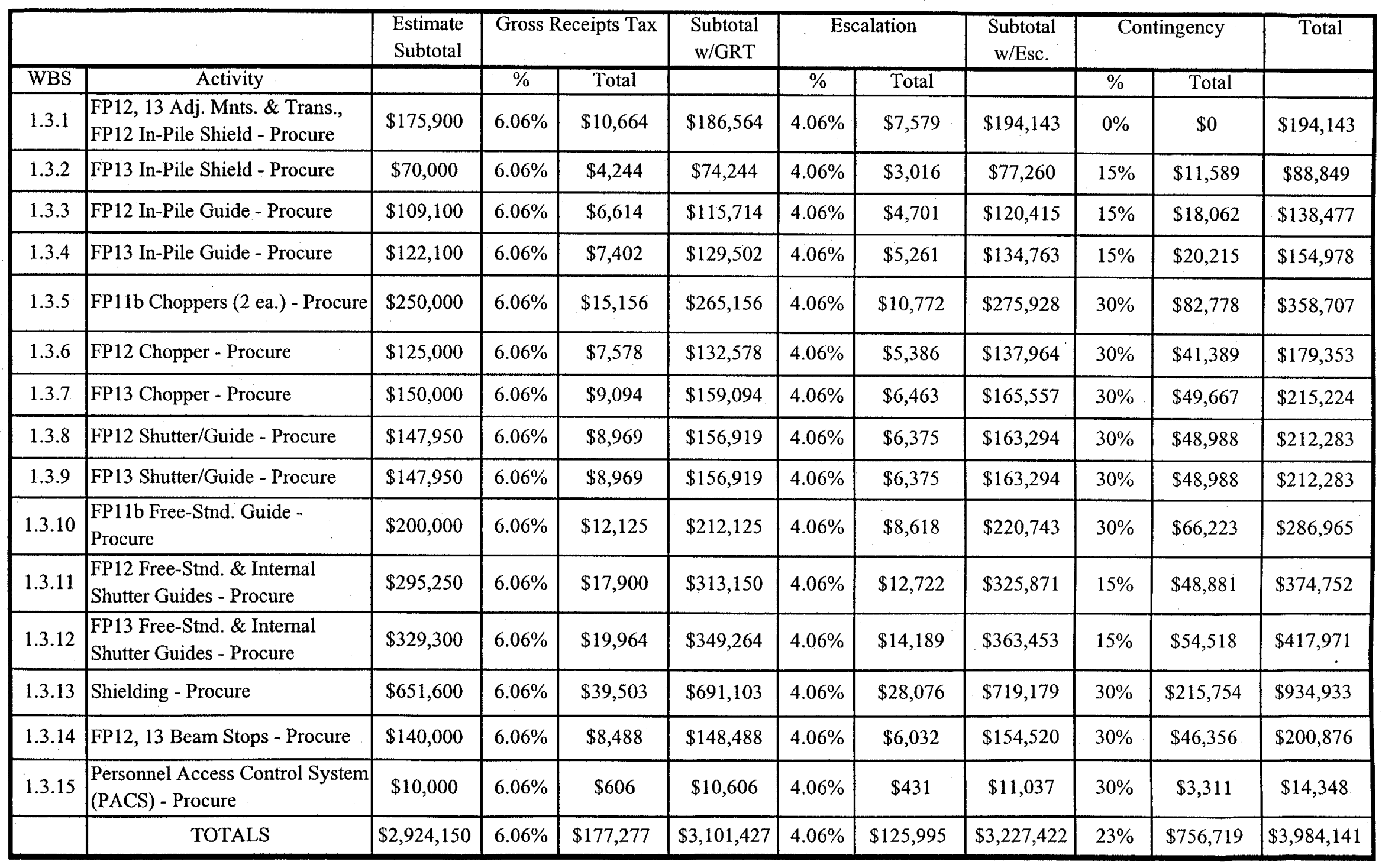


DETAILED ESTIMATING WORKSHEET BY WBS

LANSCE Lujan Center Integrated Beam Lines

$$
9901572
$$

Preliminary Cost Estimate

WBS 1.4 Construction, Installation \& Testing

\begin{tabular}{|c|c|c|c|c|c|c|c|c|c|c|c|c|c|}
\hline Description & Qty & Unit & \begin{tabular}{|c|} 
Material Unit \\
Cost
\end{tabular} & Procurement Fee & $\begin{array}{c}\text { Total } \\
\text { Material } \\
\text { Cost }\end{array}$ & $\begin{array}{l}\text { Installation } \\
\text { Unit Cost }\end{array}$ & $\begin{array}{l}\text { Equipment } \\
\text { Unit Cost }\end{array}$ & $\begin{array}{l}\text { Equipment } \\
\text { Cost }\end{array}$ & Labor Cost & $\begin{array}{c}\text { Total } \\
\text { Installation } \\
\text { Cost }\end{array}$ & Contingency $\%$ & Contingency $\$$ & Total Cost \\
\hline General Cleanup & 1 & is & $\$ 2,000.00$ & $\$ 200$ & $\$ 2,200$ & $\$ 20,000.00$ & $\$ 5,000.00$ & $\$ 5,000$ & $\$ 20,000$ & $\$ 27,200$ & $35 \%$ & $\$ 9,520$ & $\$ 36,720$ \\
\hline Equipment Mobilization & 1 & is & $\$ 0.00$ & $\$ 0$ & $\$ 0$ & $\$ 10,000.00$ & $\$ 0.00$ & $\$ 0$ & $\$ 10,000$ & $\$ 10,000$ & $35 \%$ & $\$ 3,500$ & $\$ 13, \$ 00$ \\
\hline Craft Training & 1 & is & $\$ 0.00$ & $\$ 0$ & $\$ 0$ & $\$ 20,000.00$ & $\$ 0.00$ & $\$ 0$ & $\$ 20,000$ & $\$ 20,000$ & $35 \%$ & $\$ 7,000$ & $\$ 27,000$ \\
\hline Painting & 1 & Is & $\$ 700.00$ & $\$ 70$ & $\$ 770$ & $\$ 5,000.00$ & $\$ 0.00$ & $\$ 0$ & $\$ 5,000$ & $\$ 5,770$ & $35 \%$ & $\$ 2,020$ & $\$ 7,790$ \\
\hline Waste Disposal & 1 & Is & $\$ 10,000.00$ & $\$ 1,000$ & $\$ 11,000$ & $\$ 30,000.00$ & $\$ 0.00$ & $\$ 0$ & $\$ 30,000$ & $\$ 41,000$ & $35 \%$ & $\$ 14,350$ & $\$ 55,350$ \\
\hline Survey Support & 1 & Is & $\$ 0.00$ & $\$ 0$ & $\$ 0$ & $\$ 3,000,00$ & $\$ 0.00$ & $\$ 0$ & $\$ 3,000$ & $\$ 3,000$ & $35 \%$ & $\$ 1,050$ & $\$ 4,050$ \\
\hline $\begin{array}{l}\text { FP12, } 13 \text { Thimbles \& } \\
\text { Shield Plugs - Install }\end{array}$ & 2 & ea & $\$ 0.00$ & $\$ 0$ & $\$ 0$ & $\$ 3,200.00$ & $\$ 1,000.00$ & $\$ 2,000$ & $\$ 6,400$ & $\$ 8,400$ & $35 \%$ & $\$ 2,940$ & $\$ 11,340$ \\
\hline $\begin{array}{l}\text { FP12, 13 Adj: Mnts. \& } \\
\text { In-Pile Guide/Shields - } \\
\text { Install }\end{array}$ & 2 & ea & $\$ 0.00$ & $\$ 0$ & $\$ 0$ & $\$ 8,800.00$ & $\$ 1,000.00$ & $\$ 2,000$ & $\$ 17,600$ & $\$ 19,600$ & $35 \%$ & $\$ 6,860$ & $\$ 26,460$ \\
\hline $\begin{array}{l}\text { ER-1 Floor Mods. - } \\
\text { Construct Pylons: }\end{array}$ & & & & $\$ 0$ & & & & & & & & & \\
\hline $\begin{array}{l}\text { Cut Slots (assume } 1.5 \mathrm{ft} \\
\text { thick) }\end{array}$ & 60 & If & $\$ 6.93$ & $\$ 42$ & $\$ 457$ & $\$ 8.74$ & $\$ 3.16$ & $\$ 190$ & $\$ 524$ & $\$ 1,171$ & $35 \%$ & $\$ 410$ & $\$ 1,581$ \\
\hline Excavate Holes & 8 & cy & $\$ 60.00$ & $\$ 48$ & $\$ 528$ & $\$ 267.75$ & $\$ 0.00$ & $\$ 0$ & $\$ 2,142$ & $\$ 2,670$ & $35 \%$ & $\$ 935$ & $\$ 3,605$ \\
\hline $\begin{array}{l}\text { Construct Pylon Columns } \\
\text { (includes forms, max. } \\
\text { reinforcing steel, and } \\
\text { concrete) }\end{array}$ & 8 & cy & $\$ 315.00$ & $\$ 252$ & $\$ 2,772$ & $\$ 661.50$ & $\$ 39.00$ & $\$ 312$ & $\$ 5,292$ & $\$ 8,376$ & $35 \%$ & $\$ 2,932$ & $\$ 11,308$ \\
\hline Grout column sides & 360 & sf & $\$ 5.05$ & $\$ 182$ & $\$ 2,000$ & $\$ 8.65$ & $\$ 1.00$ & $\$ 360$ & $\$ 3,114$ & $\$ 5,474$ & $35 \%$ & $\$ 1,916$ & $\$ 7,390$ \\
\hline $\begin{array}{l}\text { Pour Slabs (includes } \\
\text { forms, reinforcing steel, } \\
\text { and concrete) }\end{array}$ & 72 & sf & $\$ 6.62$ & $\$ 48$ & $\$ 524$ & $\$ 1.55$ & $\$ 1.00$ & $\$ 72$ & $\$ 112$ & $\$ 708$ & $35 \%$ & $\$ 248$ & $\$ 956$ \\
\hline $\begin{array}{l}\text { Shielding Support } \\
\text { Structure - Fabricate: }\end{array}$ & & & & $\$ 0$ & & & & & & & & & \\
\hline Cut Columns $(6 \times 28.5 \times 5)$ & 168 & if & $\$ 21.00$ & $\$ 353$ & $\$ 3,881$ & $\$ 0.00$ & $\$ 0.00$ & $\$ 0$ & $\$ 0$ & $\$ 3,881$ & $35 \%$ & $\$ 1,358$ & $\$ 5,239$ \\
\hline
\end{tabular}




\begin{tabular}{|c|c|c|c|c|c|c|c|c|c|c|c|c|c|}
\hline Description & Qty & Unit & $\begin{array}{c}\text { Material Unit } \\
\text { Cost }\end{array}$ & Procurement Fee & $\begin{array}{c}\text { Total } \\
\text { Material } \\
\text { Cost }\end{array}$ & $\begin{array}{l}\text { Installation } \\
\text { Unit Cost }\end{array}$ & $\begin{array}{l}\text { Equipment } \\
\text { Unit Cost }\end{array}$ & $\begin{array}{l}\text { Equipment } \\
\text { Cost }\end{array}$ & Labor Cost & $\begin{array}{c}\text { Total } \\
\text { Installation } \\
\text { Cost }\end{array}$ & Contingency \% & Contingency \$ & Total Cost \\
\hline Cut Beams(6x20wf×5) & 160 & If & $\$ 14.75$ & $\$ 236$ & $\$ 2,596$ & $\$ 0.00$ & $\$ 0.00$ & $\$ 0$ & $\$ 0$ & $\$ 2,596$ & $35 \%$ & $\$ 909$ & $\$ 3,505$ \\
\hline Cut Beams (7x68wtx5) & 476 & If & $\$ 16.75$ & $\$ 797$ & $\$ 8,770$ & $\$ 0.00$ & $\$ 0.00$ & \$0 & $\$ 0$ & $\$ 8,770$ & $35 \%$ & $\$ 3,070$ & $\$ 11,840$ \\
\hline $\begin{array}{l}\text { FP12, 13 Beam Stops - } \\
\text { Install \& Remove }\end{array}$ & 2 & ea & $\$ 0.00$ & $\$ 0$ & $\$ 0$ & $\$ 12,800.00$ & $\$ 500.00$ & $\$ 1,000$ & $\$ 25,600$ & $\$ 26,600$ & $35 \%$ & $\$ 9,310$ & $\$ 35,910$ \\
\hline $\begin{array}{l}\text { FP 11b Choppers - } \\
\text { Install }\end{array}$ & 2 & ea & $\$ 0.00$ & $\$ 0$ & $\$ 0$ & $\$ 3,200.00$ & $\$ 500.00$ & $\$ 1,000$ & $\$ 6,400$ & $\$ 7,400$ & $35 \%$ & $\$ 2,590$ & $\$ 9,990$ \\
\hline FP12 Chopper - Install & 1 & ea & $\$ 0.00$ & $\$ 0$ & $\$ 0$ & $\$ 3,200.00$ & $\$ 500.00$ & $\$ 500$ & $\$ 3,200$ & $\$ 3,700$ & $35 \%$ & $\$ 1,295$ & $\$ 4,995$ \\
\hline FP13 Chopper - Install & 1 & ea & $\$ 0.00$ & $\$ 0$ & $\$ 0$ & $\$ 3,200.00$ & $\$ 500.00$ & $\$ 500$ & $\$ 3,200$ & $\$ 3,700$ & $35 \%$ & $\$ 1,295$ & $\$ 4,995$ \\
\hline $\begin{array}{l}\text { FP12 Shutter/Guide - } \\
\text { Install }\end{array}$ & 1 & ea & $\$ 0.00$ & $\$ 0$ & $\$ 0$ & $\$ 11,200.00$ & $\$ 500.00$ & $\$ 500$ & $\$ 11,200$ & $\$ 11,700$ & $35 \%$ & $\$ 4,095$ & $\$ 15,795$ \\
\hline $\begin{array}{l}\text { FP13 Shutter/Guide - } \\
\text { Install }\end{array}$ & 1 & ea & $\$ 0.00$ & $\$ 0$ & $\$ 0$ & $\$ 11,200.00$ & $\$ 500.00$ & $\$ 500$ & $\$ 11,200$ & $\$ 11,700$ & $35 \%$ & $\$ 4,095$ & $\$ 15,795$ \\
\hline Utilities - Install: & & & & $\$ 0$ & & & & & & & & & \\
\hline Electrical Connections & 1 & Is & $\$ 2,000.00$ & $\$ 200$ & $\$ 2,200$ & $\$ 20,000.00$ & $\$ 500.00$ & $\$ 500$ & $\$ 20,000$ & $\$ 22,700$ & $35 \%$ & $\$ 7,945$ & $\$ 30,645$ \\
\hline Pneumatic Connections & 1 & is & $\$ 2,000.00$ & $\$ 200$ & $\$ 2,200$ & $\$ 15,000.00$ & $\$ 0.00$ & $\$ 0$ & $\$ 15,000$ & $\$ 17,200$ & $35 \%$ & $\$ 6,020$ & $\$ 23,220$ \\
\hline Hardware Tests & 1 & Is & $\$ 0.00$ & $\$ 0$ & $\$ 0$ & $\$ 35,770.00$ & $\$ 500.00$ & $\$ 0$ & $\$ 35,770$ & $\$ 35,770$ & $35 \%$ & $\$ 12,520$ & $\$ 48,290$ \\
\hline $\begin{array}{l}\text { Shielding \& Support } \\
\text { Structure - Install: }\end{array}$ & & & & $\$ 0$ & & & & & & & & & \\
\hline $\begin{array}{l}\text { Install Steel Colums and } \\
\text { Beams }\end{array}$ & 8 & $t$ & $\$ 0.00$ & $\$ 0$ & $\$ 0$ & $\$ 455.00$ & $\$ 216.00$ & $\$ 1,728$ & $\$ 3,640$ & $\$ 5,368$ & $35 \%$ & $\$ 1,879$ & $\$ 7,247$ \\
\hline Place Shield Plates & 1 & Is & $\$ 0.00$ & $\$ 0$ & $\$ 0$ & $\$ 35,000,00$ & $\$ 4,000.00$ & $\$ 4,000$ & $\$ 35,000$ & $\$ 39,000$ & $35 \%$ & $\$ 13,650$ & $\$ 52,650$ \\
\hline $\begin{array}{l}\text { Construction Support } \\
(10 \%)\end{array}$ & 1 & lot & $\$ 0.00$ & $\$ 0$ & $\$ 0$ & $\$ 0.00$ & $\$ 0.00$ & $\$ 0$ & $\$ 0$ & $\$ 33,329$ & $35 \%$ & $\$ 11,665$ & $\$ 44,994$ \\
\hline TOTALS & & & & & $\$ 39,898$ & & & $\$ 20,162$ & $\$ 293,394$ & $\$ 386,783$ & $35 \%$ & & \\
\hline & & & & & & & & & & $6.06 \%$ & & & \\
\hline & & & & & & \multicolumn{3}{|c|}{ Gross Receipts Tax@6.065\% } & & $\$ 23,449$ & & & \\
\hline & & & & & & \multicolumn{3}{|c|}{ Subtotal with GRT } & & $\$ 410,232$ & & & \\
\hline
\end{tabular}




\begin{tabular}{|c|c|c|c|c|c|c|c|c|c|c|c|c|c|}
\hline Description & Qty & Unit & $\begin{array}{c}\text { Material Unit } \\
\text { Cost }\end{array}$ & Procurement Fee & $\begin{array}{c}\text { Total } \\
\text { Material } \\
\text { Cost } \\
\end{array}$ & $\begin{array}{c}\text { Installation } \\
\text { Unit Cost }\end{array}$ & $\begin{array}{c}\text { Equipment } \\
\text { Unit Cost }\end{array}$ & $\begin{array}{c}\text { Equipment } \\
\text { Cost }\end{array}$ & Labor Cost & $\begin{array}{c}\text { Total } \\
\text { Installation } \\
\text { Cost }\end{array}$ & Contingency \% & Contingency \$ & Total Cost \\
\hline & & & & & & & & & & & & & \\
\hline & & & & & & & & & & $4.06 \%$ & & & \\
\hline & & & & & & \multicolumn{3}{|c|}{ Escalation@ $9.06 \%$} & & $\$ 16,655.41$ & & & \\
\hline & & & & & & \multicolumn{3}{|c|}{ Subtotal with Escalation } & & $\$ \$ 426,887$ & $35 \%$ & $\$ 149,411$ & $\$ 576,298$ \\
\hline
\end{tabular}

$\mathrm{ACR}=\mathrm{Acre}$

$c y=$ Cubic yard

ea=Each

$\mathrm{ft}=\mathrm{Foot}$

If =Linear foot

Is=Lump sum

sf $\mathrm{f}=$ Square foot

$\mathrm{t}=\mathrm{T}$ on 
DETAILED ESTIMATING WORKSHEET BY WBS

LANSCE Lujan Center Integrated Beam Lines 9901572

Preliminary Cost Estimate

WBS 1.5 Safety/Regulatory Activities

\begin{tabular}{|c|c|c|c|c|c|c|c|c|c|c|c|}
\hline \multicolumn{2}{|r|}{ Safety/Regulatory Support } & \multirow{2}{*}{$\begin{array}{l}\text { Estimate } \\
\text { Subtotal }\end{array}$} & \multicolumn{2}{|c|}{ Gross Receipts Tax } & \multirow{2}{*}{$\begin{array}{c}\text { Subtotal } \\
\text { w/GRT }\end{array}$} & \multicolumn{2}{|c|}{ Escalation } & \multirow{2}{*}{$\begin{array}{c}\text { Subtotal } \\
\text { w/Esc. }\end{array}$} & \multicolumn{2}{|c|}{ Contingency } & \multirow[t]{2}{*}{ Total } \\
\hline$\overline{\text { WBS }}$ & Activity & & $\%$ & Total & & $\%$ & Total & & $\%$ & Total & \\
\hline 1.5 & Safety/Regulatory Activities & $\$ 84,182$ & $6.06 \%$ & $\$ 5,104$ & $\$ 89,286$ & $4.06 \%$ & $\$ 3,625$ & $\$ 92,911$ & $35 \%$ & $\$ 32,519$ & $\$ 125,430$ \\
\hline & TOTALS & $\$ 84,182$ & $6.06 \%$ & $\$ 5,104$ & $\$ 89,286$ & $4.06 \%$ & $\$ 3,625$ & $\$ 92,911$ & $35 \%$ & $\$ 32,519$ & $\$ 125,430$ \\
\hline
\end{tabular}


DETAILED ESTIMATING WORKSHEET BY WBS

LANSCE Lujan Center Integrated Beam Lines

9901572

Preliminary Cost Estimate

LANL BURDENS

\begin{tabular}{|c|c|c|c|c|c|c|c|}
\hline WBS & Contract Description & $\begin{array}{l}\text { Contract } \\
\text { Amount }\end{array}$ & Funds Type & $\begin{array}{c}\text { Procurement } \\
\text { Rate }^{*}(3.25 \%)\end{array}$ & $\begin{array}{c}\text { LANSCE Div. \& } \\
\text { Grp. Support* } \\
71.3 \% \text { Exp. } \\
\text { 0\% Cap. } \\
71.3 \% \text { LDRD }\end{array}$ & $\begin{array}{c}\text { G\&A** } \\
42 \% \text { Exp. } \\
14 \% \text { Cap. } \\
0 \% \text { LDRD }\end{array}$ & Total Burden \\
\hline \multirow[t]{2}{*}{1.1} & Project Management & $\$ 289,128$ & Cap & $\$ 0$ & $\$ 0$ & $\$ 40,478$ & $\$ 40,478$ \\
\hline & & & & & & Total & $\$ 40,478$ \\
\hline \multirow[t]{2}{*}{1.2} & Design Activities & $\$ 1,200,775$ & Cap & $\$ 39,025$ & $\$ 0$ & $\$ 173,572$ & $\$ 212,597$ \\
\hline & & & & & & Total & $\$ 212,597$ \\
\hline & & & & & & & \\
\hline \multirow[t]{2}{*}{1.3} & Procurement & $\$ 3,984,141$ & Cap & $\$ 129,485$ & $\$ 0$ & $\$ 575,908$ & $\$ 705,392$ \\
\hline & & & & & & Total & $\$ 705,392$ \\
\hline & & & & & & & \\
\hline \multirow[t]{2}{*}{1.4} & $\begin{array}{l}\text { Construction, Installation } \\
\& \text { Testing }\end{array}$ & $\$ 576,298$ & Cap & $\$ 18,730$ & $\$ 0$ & $\$ 83,304$ & $\$ 102,034$ \\
\hline & & & & & & Total & $\$ 102,034$ \\
\hline & & & & & & & \\
\hline \multirow[t]{4}{*}{1.5} & $\begin{array}{l}\text { Safety/Regulatory } \\
\text { Activities }\end{array}$ & $\$ 125,430$ & Cap & $\$ 0$ & $\$ 0$ & $\$ 17,560$ & $\$ 17,560$ \\
\hline & & & & & & Total & $\$ 17,560$ \\
\hline & & & & & & & \\
\hline & & & & & \multicolumn{2}{|c|}{ GRAND TOTAL } & $\$ 1,078,061$ \\
\hline
\end{tabular}

* Based on guidelines from the Financial Management Handbook, and input from LANL personnel.

** G\&A only applied on the first $\$ 100,000$ of each contract value. For this estimate, all contracts assumed to be less than $\$ 100 \mathrm{k}$ so G\&A is applied to total amount.

Note: LANL burdens were applied to contingency funds. 